\title{
Persistence of the Fetal Pattern of Tropoelastin Gene Expression in Severe Neonatal Bovine Pulmonary Hypertension
}

Kurt R. Stenmark, * Anthony G. Durmowicz, * Jill D. Roby, ${ }^{\star}$ Robert P. Mecham, ${ }^{\text {*8 }}$ and William C. Parks

${ }^{*}$ Developmental Lung Biology and Pediatric Critical Care Medicine, University of Colorado Health Sciences Center, Denver, Colorado 80262; and ${ }^{\ddagger}$ Departments of Medicine, and ${ }^{\S}$ Cell Biology and Physiology, Washington University Medical Center,

St. Louis, Missouri 63110

\section{Abstract}

Neonatal hypoxic pulmonary hypertension causes increases and spatial changes in tropoelastin expression in pulmonary arteries. However, it is not clear if this is due to recruitment of quiescent smooth muscle cells (SMC) into an elastin-producing phenotype or persistence of the fetal pattern of tropoelastin gene expression. We evaluated the distribution and relative concentration of tropoelastin mRNA in intralobar pulmonary arteries from late gestation fetuses and in animals exposed to hypobaric hypoxia ( $430 \mathrm{mmHg}$ ) from birth for $1,3,7$, or $14 \mathrm{~d}$, as well as in age-matched and adult room air-breathing controls. In situ hybridization demonstrated that tropoelastin mRNA was distributed throughout the entire radius of the pulmonary vessel wall in the fetus and newborn calf. By $15 \mathrm{~d}$ of age, only cells in the inner third of the media expressed tropoelastin mRNA, and by adulthood no tropoelastin mRNA was detected in the vessel wall. These findings demonstrated that tropoelastin expression shuts off in a spatially specific pattern, moving from the abluminal to the luminal side of the medial in the neonatal pulmonary artery when pressures and resistance are falling. In the aorta of 15-d-old calves, tropoelastin mRNA expression was seen equally throughout the media, indicating tissue-specific regulation of elastin in the neonatal period. In contrast, intralobar pulmonary arteries from calves exposed to hypoxia, which prevented the normal postnatal decline in pulmonary artery pressure, maintained the fetal pattern and levels of tropoelastin mRNA expression at all time points. Thus, rather than causing a recruitment of SMC into an elastin-producing phenotype, neonatal pulmonary hypertension caused a persistence of the fetal pattern of tropoelastin expression in medial SMC. Cell-free translation showed that the same tropoelastin isoforms were made by mRNA from control and hypertensive calves and, unlike the ligamentum nuchae, did not change during the transition from fetal to neonatal life. We conclude that pulmonary hypertension in the neonate perturbs the normal postpartum repression of tropoelastin expression resulting in a persistence of the fetal spacial and isoform patterns of tropoelastin gene expression. (J. Clin. Invest. 1994. 93:1234-1242.) Key words: vascular development • extracellu-

Address correspondence to Dr. Kurt R. Stenmark, Developmental Lung Biology, University of Colorado HSC, 4200 East 9th Avenue. B133, Denver, CO 80262.

Received for publication 17 June 1993 and in revised form 20 September 1993.

J. Clin. Invest.

(c) The American Society for Clinical Investigation, Inc. 0021-9738/94/03/1234/09 \$2.00

Volume 93, March 1994, 1234-1242 lar matrix proteins $\bullet$ smooth muscle cells $\bullet$ vascular remodeling • pulmonary hypertension

\section{Introduction}

Pulmonary hypertension in both humans and animals is characterized by significant increases in cell proliferation and extracellular matrix protein production in pulmonary vascular wall cells (1-4). The fibroproliferative response in neonatal pulmonary hypertension is particularly exuberant compared with changes observed in adults, yet the reasons for these age-related differences remain unexplained. With respect to extracellular matrix proteins, tropoelastin production is developmentally regulated, and elastogenesis in arteries is limited to a brief period from mid-fetal to early neonatal life (5-8). Further, developmental regulation of matrix protein production in the vasculature appears to be influenced to a large degree by hemodynamic forces (9-11). Thus, because hemodynamic factors modulate arterial growth and protein synthesis, and because there are large and abrupt changes in hemodynamic function in the pulmonary vascular bed around the time of birth, we hypothesized that major changes in the expression of tropoelastin mRNAs should take place in the perinatal period. Study of matrix protein gene expression in the normal and hypertensive neonatal pulmonary circulation should provide clues as to the mechanisms responsible for regulating arterial growth and matrix production.

Our previous studies have demonstrated marked increases in both elastin and collagen synthesis and steady state mRNA levels in pulmonary artery tissue and cells from hypertensive neonatal animals $(12,13)$. Further, we have demonstrated marked differences in the distribution of cells producing elastin in the pulmonary arteries of neonatal calves with pulmonary hypertension compared with controls. In 15-d-old control animals, in situ hybridization signal for tropoelastin mRNA was localized in the inner third of the media. In hypertensive vessels, hybridization signal was observed throughout the entire media of the vessel, with the strongest signal seen in the outer media (14). Based on these findings, we initially hypothesized that smooth muscle cells (SMC) ${ }^{1}$ in the outer vessel wall were rapidly recruited into an elastin-producing phenotype. This could have been due to an increase in the responsiveness of these cells to local humoral or mechanical stimuli. Alternatively, the pattern of tropoelastin gene expression may be due to a persistence of a fetal pattern of gene expression that is maintained in the face of the persistence of high pressures in the pulmonary circulation similar to the fetus.

To better understand the mechanisms governing the arterial remodeling associated with neonatal pulmonary hyperten-

1. Abbreviation used in this paper: SMC, smooth muscle cell. 
sion, we sought to define the normal pattern of tropoelastin gene expression in elastic pulmonary arteries in late fetal and early neonatal life and to examine the impact of severe neonatal pulmonary hypertension on tropoelastin mRNA expression in these vessels. Using in situ hybridization and Northern blot analyses, we found that the distribution and quantity of tropoelastin mRNA in lobar pulmonary arteries changed dramatically from the late gestation fetus through the early neonatal period in control animals but was unchanged in animals exposed to hypobaric hypoxia from birth. Thus, we showed that the fetal pattern of tropoelastin mRNA expression persists in the neonatal hypertensive state. Additionally, we demonstrated the existence of a radial gradient of elastin expression during normal postnatal adaptation in the pulmonary artery. These perinatal changes are specific to the pulmonary vasculature since no age-related spatial alterations in tropoelastin mRNA expression were observed in the aorta over the same time period.

\section{Methods}

Animal model. 33 newborn male dairy calves obtained from the dairy herd of the Duo Dairy (Fort Collins, CO) were used in these studies. In addition, tissues from five late gestation (240-270 d) fetal calves, and three adult ( $>2$ yr) steers were examined. Newborn calves that served as normoxic controls during the normal transition to extrauterine life were housed indoors and cared for as previously described (15). Animals were studied at $4 \mathrm{~h}(n=3), 2 \mathrm{~d}(n=3), 4 \mathrm{~d}(n=3), 8 \mathrm{~d}(n=3)$, and $15 \mathrm{~d}(n=5)$ of life. Experimental animals, in which the intent was to prevent the normal adaptation of the pulmonary circulation to extrauterine life, were made hypertensive by exposure to hypobaric hypoxia (barometric pressure $\left[P_{B}\right]=430 \mathrm{mmHg}$, equivalent to an altitude of $4,300 \mathrm{~m})$. These calves were placed in a hypobaric chamber $(3 \times 9$ m) at the Department of Physiology, Colorado State University, within the first $24 \mathrm{~h}$ of life and cared for as previously described (15). The calves ( $n=3$ in each group, except at $14 \mathrm{~d}$, where $n=7$ ) remained in the chamber for $1,3,7$, or $14 \mathrm{~d}$, and at the end of the exposure period, hemodynamic measurements were made, the animal was killed by pentobarbital overdose and exsanguination, and lobar pulmonary vascular tissue was obtained for both RNA isolation and in situ hybridization studies. This treatment protocol allowed for comparisons between control and experimental groups in age-matched animals. The animal exposure protocol was approved by the University of Colorado Animal Research Review Board.

Hemodynamic studies. Hemodynamic studies were performed in all control and hypertensive newborn calves. All hemodynamic studies were performed in awake, nonanesthetized animals in the left lateral recumbent position. Using local lidocaine anesthesia, a dual thermistor 7Fr Swan-Ganz catheter (Nova Dual Therm, Berlin, NJ) was placed into the pulmonary artery percutaneously via the external jugular vein using the Seldinger technique. Correct placement was determined by pressure wave contour. An aortic catheter (PE-200; Clay Adams, Parsippany, NJ) was introduced via the left saphenous artery, which had been surgically exposed using local lidocaine anesthesia. Pressures were measured with disposable transducers (Sorensen Transpae, North Chicago, IL) and continuously recorded on a four-channel recorder. Measurements were made at $P_{\mathrm{B}}=630 \mathrm{mmHg}$ for control calves (ambient altitude, Fort Collins, $\mathrm{CO}$ ) and $P_{\mathrm{B}}=430 \mathrm{mmHg}$ for experimental (hypoxic, pulmonary hypertensive) animals.

Tissue preparation and in situ hybridization. Immediately after death of the calf, the heart and lungs were removed en bloc. The right caudal lobe was dissected free and was fixed at room temperature with $10 \%$ neutral buffered formalin by perfusion of the pulmonary artery at a vascular pressure approximately equal to that recorded in vivo and of the lobar bronchus at a pressure of $\sim 30 \mathrm{~cm} \mathrm{H}_{2} \mathrm{O}$ for 30-60 min followed by immersion in fixative overnight at $4^{\circ} \mathrm{C}$. Lung specimens were then washed, perfused, and stored at $4^{\circ} \mathrm{C}$ in $70 \%$ ethanol until tissue samples were dissected and processed for paraffin embedding. Tissues for in situ hybridization were taken from the lobar pulmonary artery between the hilum and third order branch. For RNA isolation, the first generation left lobar pulmonary artery was obtained from fresh lung tissue, cleaned of adventitia, placed in a $50-\mathrm{ml}$ sterile plastic conical tube, and immersed in liquid nitrogen. Samples were stored at $-70^{\circ} \mathrm{C}$ until used for RNA isolation.

In situ hybridization studies were performed in all calves and were done essentially as previously described by our laboratories (14). Sections for hybridization were cut at $5 \mu \mathrm{m}$, picked up on Superfrost Plus slides (Fisher Scientific, Pittsburgh, PA), deparaffinized in xylene, dehydrated through graded ethanols, and rehydrated in PBS. All sections were treated with $1 \mu \mathrm{g} / \mathrm{ml}$ nuclease-free proteinase K (Sigma Chemical Co., St. Louis, MO) to loosen the constraints of intracellular crosslinks caused by aldehyde fixation, and were washed in freshly prepared 0.1 $\mathrm{M}$ triethanolamine buffer containing $0.25 \%$ acetic anhydride to reduce potential nonspecific binding sites. Sections were covered with 25-50 $\mu \mathrm{l}$ of hybridization buffer containing $50 \%$ deionized formamide, $2 \times$ standard saline-citrate buffer ( $\mathrm{SSC}$; $1 \times$ is $150 \mathrm{mM} \mathrm{NaCl}, 15 \mathrm{mM}$ sodium citrate, $\mathrm{pH} 7.0$ ), $20 \mathrm{mM}$ Tris- $\mathrm{HCl}, \mathrm{pH} 8.0,1 \times$ Denhardt's solution, $1 \mathrm{mM}$ EDTA, $10 \%$ dextran sulfate, $100 \mathrm{mM}$ DTT, $0.5 \mathrm{mg} / \mathrm{ml}$ yeast RNA, and $2.5 \times 10^{4} \mathrm{cpm} / \mu \mathrm{l}$ of ${ }^{35} \mathrm{~S}$-labeled tropoelastin RNA probe. To retain the hybridization solution, sections were covered with siliconized, autoclaved coverslips sealed with a 1:10 mixture of petroleum ether and rubber cement. Sections were incubated at $55^{\circ} \mathrm{C}$ for 18 $h$ in a humidified chamber.

After hybridization, slides were washed under stringent conditions as previously described (14), except that $10 \mathrm{mM}$ DTT was substituted for $25 \mathrm{mM} \beta$-mercaptoethanol in the wash solutions. Nonspecific binding was reduced by incubating the slides in $0.5 \mathrm{M} \mathrm{NaCl}, 10 \mathrm{mM}$ Tris$\mathrm{HCl}, \mathrm{pH}$ 8.0, $1 \mathrm{mM}$ EDTA containing $20 \mu \mathrm{g} / \mathrm{ml}$ RNase-A (Sigma Chemical Co.) at $37^{\circ} \mathrm{C}$ for $30 \mathrm{~min}$. Washed slides were dipped in $\mathrm{Ko}-$ dak NTB-2 emulsion diluted 1:1 with distilled water and processed for autoradiography as described (14). For the comparisons made in this study, exposure was for $12 \mathrm{~d}$ so relative signal strength could be compared. After development of the photographic emulsion, slides were stained with hematoxylin-eosin. Silver grains were visualized by darkfield microscopy.

Preparation of RNA probes. For in situ hybridization, tropoelastin mRNA was detected by hybridization with a radiolabeled antisense RNA probe transcribed from a 500-bp bovine cDNA, T66. T66 is a 500-bp cDNA of the bovine elastin gene spanning exons 16-21. As a negative control, sense T66 RNA was synthesized and hybridized as well. In vitro transcribed RNA was labeled with $\left[{ }^{35}\right.$ S]UTP $(>1,200$ $\mathrm{Ci} / \mathrm{mMol}$; New England Nuclear, Boston, MA) under conditions recommended by and with reagents from Promega Biotec (Madison, WI), except that the transcription reaction was extended to $4 \mathrm{~h}$ to allow for the relatively inefficient incorporation of sulfated ribonucleotides. $\mathrm{Cal}-$ culated probe specific activities were between $10^{8}$ and $10^{9} \mathrm{dpm} / \mu \mathrm{g}$. RNA probes were prepared and purified as previously described (14).

$R N A$ hybridization. Total RNA was isolated by homogenization of frozen artery segments in guanidine thiocyanate and centrifugation through cesium chloride, and Northern hybridization and washes were done under stringent conditions as previously described (12-14). Total RNA ( $5 \mu \mathrm{g} /$ lane ), $n=2$ at each time point, was denatured, fractionated through an agarose-formaldehyde gel, and transferred to nitrocellulose filters. Tropoelastin cDNA T66 was labeled with $\alpha-\left[{ }^{32} \mathrm{P}\right] \mathrm{dCTP}$ by nick translation. Autoradiographic signal was quantified by densitometry and normalized to the relative amount of $28 \mathrm{~S}$ rRNA detected with an oligomer (5'GGGCTGGGCCTCGATCAGAAGGACTTGG 3 ") complementary to sequences that are conserved among mammalian 28S rRNA subunits (16). Oligomer preparation, purification, labeling with $\gamma-\left[{ }^{32} \mathrm{P}\right] \mathrm{ATP}$, and hybridization and wash conditions were performed as previously described (17). Autoradiography for $28 \mathrm{~S}$ rRNA Northerns was between 15 and $45 \mathrm{~min}$.

Cell-free translation. Total RNA ( $5 \mu \mathrm{g}$ ) purified from lobar pulmonary artery and nuchal ligament from 270-d-old bovine fetuses and 
from 15-d-old normoxic and 14-d-old hypertensive calves was translated in a rabbit reticulocyte lysate (Promega Biotec) using $\mathrm{L}-\left[{ }^{3} \mathrm{H}\right]-$ leucine or $\mathrm{L}-\left[{ }^{35} \mathrm{~S}\right]$ cysteine. Tropoelastin peptides were specifically immunoprecipitated with a monoclonal anti-bovine tropoelastin antibody, and the immunoprecipitated protein was resolved by electrophoresis through thin, continuous gradient SDS-polyacrylamide gels and detected by fluorography as described (17).

\section{Results}

Hemodynamics. Previously, we reported that chronic hypoxia ( $15 \mathrm{~d}$ ) results in severe pulmonary hypertension, and we have described in detail the hemodynamic changes associated with this exposure $(15,18)$. To study the temporal pattern of these changes, we placed newborn calves at simulated high altitude for 1-15 d and monitored changes in hemodynamics and tropoelastin mRNA expression and compared them with agematched controls. A steady decline in pulmonary artery pressure was observed in control calves over the first $15 \mathrm{~d}$ of life. Pressures declined from a mean of $62 \pm 5 \mathrm{mmHg}$ at $4 \mathrm{~h}$ of postuterine life to $27 \pm 2 \mathrm{mmHg}$ by $15 \mathrm{~d}$ of life (Fig. 1). In animals made continuously hypoxic from the first day of life, in agreement with our prior studies $(15,18)$, no such decline was observed, and, in fact, we noted that pulmonary artery pressures at $14 \mathrm{~d}$ of hypobaric hypoxic exposure greatly exceeded those in the newborn (Fig. 1) or those reported for the fetus (19). Over this time period, systemic pressure remained constant at $\sim 85 \mathrm{mmHg}$.

In situ hybridization. Because elastin is the principal matrix component of large conducting arteries, tropoelastin mRNA expression provides a reliable marker of vascular SMC phenotype during normal and abnormal growth and development. In the late gestation fetus (240-270 d), tropoelastin mRNA was expressed by cells throughout the media of the lobar artery, but, the relative signal strength varied within the vessel wall. The strongest signal was detected in outer medial SMC, which were separated by dense foci of tropoelastin mRNA-negative cells (Fig. $2 A$ ). Consistent with a lack of detectable tropoelastin mRNA, these outer medial cell foci were also devoid of well-developed elastic laminae, as seen in the bright-field illuminated photomicrograph (Fig. $2 B$ ). Inner medial cells, as well as some endothelial cells, of the fetal lobar arteries were consistently positive for tropoelastin mRNA. The signal per cell, however, appeared less in areas closer towards the vessel lumen, indicating a radial gradient of tropoelastin mRNA expression. In addition, the hybridization pattern in the innermost part of the arterial wall was more random and punctuate rather than consistently between lamellae as in the outer media. These features of tropoelastin expression were seen in all five late gestation fetal animals studied. Arteries from several $(n=3)$ 4-5-h-old newborn calves had essentially the same morphology and pattern of tropoelastin expression as that seen in the fetal vessel (Fig. 2 D). No hybridization signal was seen in samples processed with radiolabeled sense RNA probe (Fig. $2 C$ ).

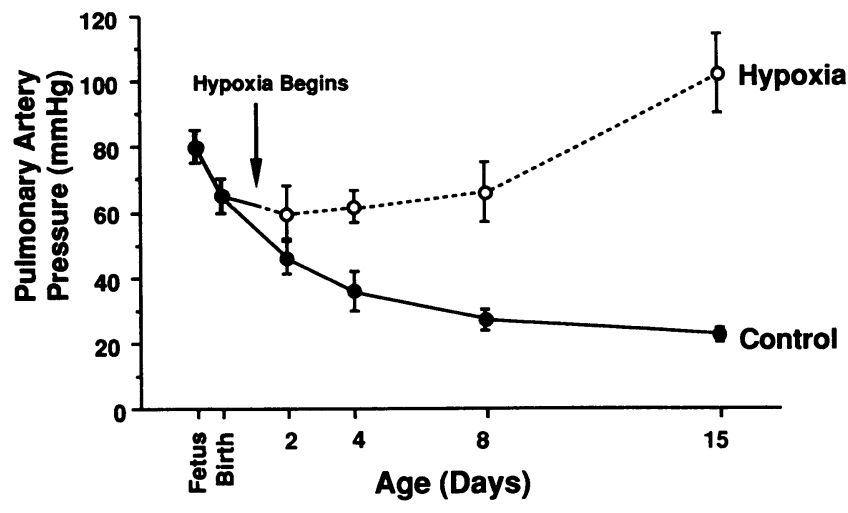

Figure 1. Exposure to hypoxia prevents the normal decline in pulmonary artery pressure that takes place during early neonatal life. A rapid decline in pulmonary artery pressure is observed in animals born and residing at $1,500 \mathrm{~m}(\bullet$, control $)$. When calves are made chronically hypoxic beginning on day 1 of life, $(0$, hypoxia), the normal decline in pressure is prevented, and by 2 wk of life, pulmonary artery pressures are greater than those observed in the fetus and even exceed those measured in the systemic circulation (mean aortic pressure, $85 \pm 5 \mathrm{mmHg}$ at $15 \mathrm{~d}$ of age).

After birth, the wall of the lobar pulmonary artery gradually thinned, and the pattern of tropoelastin expression was markedly altered in normal animals. At $2 \mathrm{~d}$ postpartum, arteries from normoxic calves demonstrated some thinning but continued to resemble fetal vessels both in the pattern and level of tropoelastin expression (Fig. 3, NA). By $4 \mathrm{~d}$ postpartum, the vessel had thinned significantly, and the signal intensity for tropoelastin mRNA was diminished. In addition, tropoelastin expression was seen mostly in middle medial cells. At $8 \mathrm{~d}$ after birth, no additional thinning of the artery or reduction in tropoelastin mRNA expression was evident. In 15-d-old neonatal calves, however, a marked change in the distribution of tropoelastin expression was seen (Fig. 3, NA). Unlike earlier ages, little to no signal was typically seen in outer medial wall cells but was consistently seen within cells in the first few layers of the inner media. This pattern was observed in four of five normoxic calves and is consistent with our previously published findings (14). In one 15-d-old normal calf, the pattern of tropoelastin mRNA expression was similar to that seen in the 8-d-old sample (not shown). By maturity, no consistent hybridization signal was observed in the lobar pulmonary artery (Fig. 4).

In the hypoxic calves, however, these age-dependent changes in pulmonary vessel morphology and tropoelastin expression did not occur. Instead, the fetal and early neonatal pattern of tropoelastin expression and wall thickness persisted after $1,3,7$, and $14 \mathrm{~d}$ of hypoxia exposure (Fig. 3, $H A$ ). Consistent among fetal, early neonatal, and all hypertensive arteries was the relative wall thickness, the increasing gradient of tropoelastin mRNA expression from the inner to outer media, and the presence of foci of tropoelastin mRNA-negative cells

Figure 2. In situ hybridizations demonstrating the fetal and neonatal distribution of tropoelastin mRNA in lobar pulmonary arteries. $(A)$ Darkfield photomicrograph demonstrating the pattern of tropoelastin mRNA hybridization in a late gestation fetus ( $270 \mathrm{~d}$ old). The strongest signal was detected in outer medial SMC, which were separated by dense foci of tropoelastin mRNA, negative cells. $(B)$ Bright-field photomicrograph of the same field shown in $A$ demonstrating the histologic configuration of this vessel. $(C)$ Dark-field photomicrograph of the same fetal lobar pulmonary artery processed with a radiolabeled sense RNA probe. $(D)$ Dark-field photomicrograph of a lobar pulmonary artery from a newborn calf $(4 \mathrm{~h}$ old $)$ demonstrating essentially the same morphology and pattern of tropoelastin expression as that seen in the fetal vessel. 

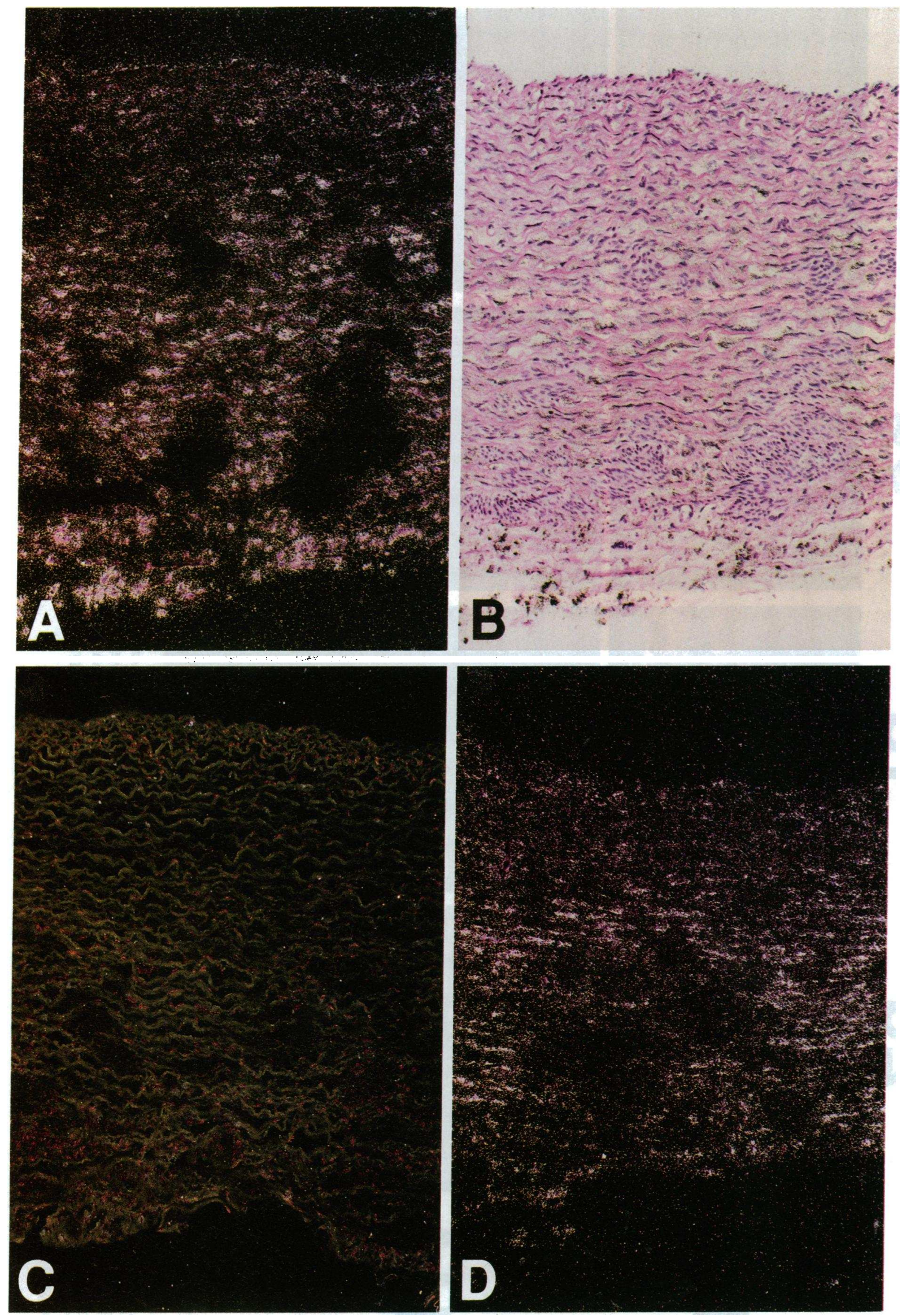

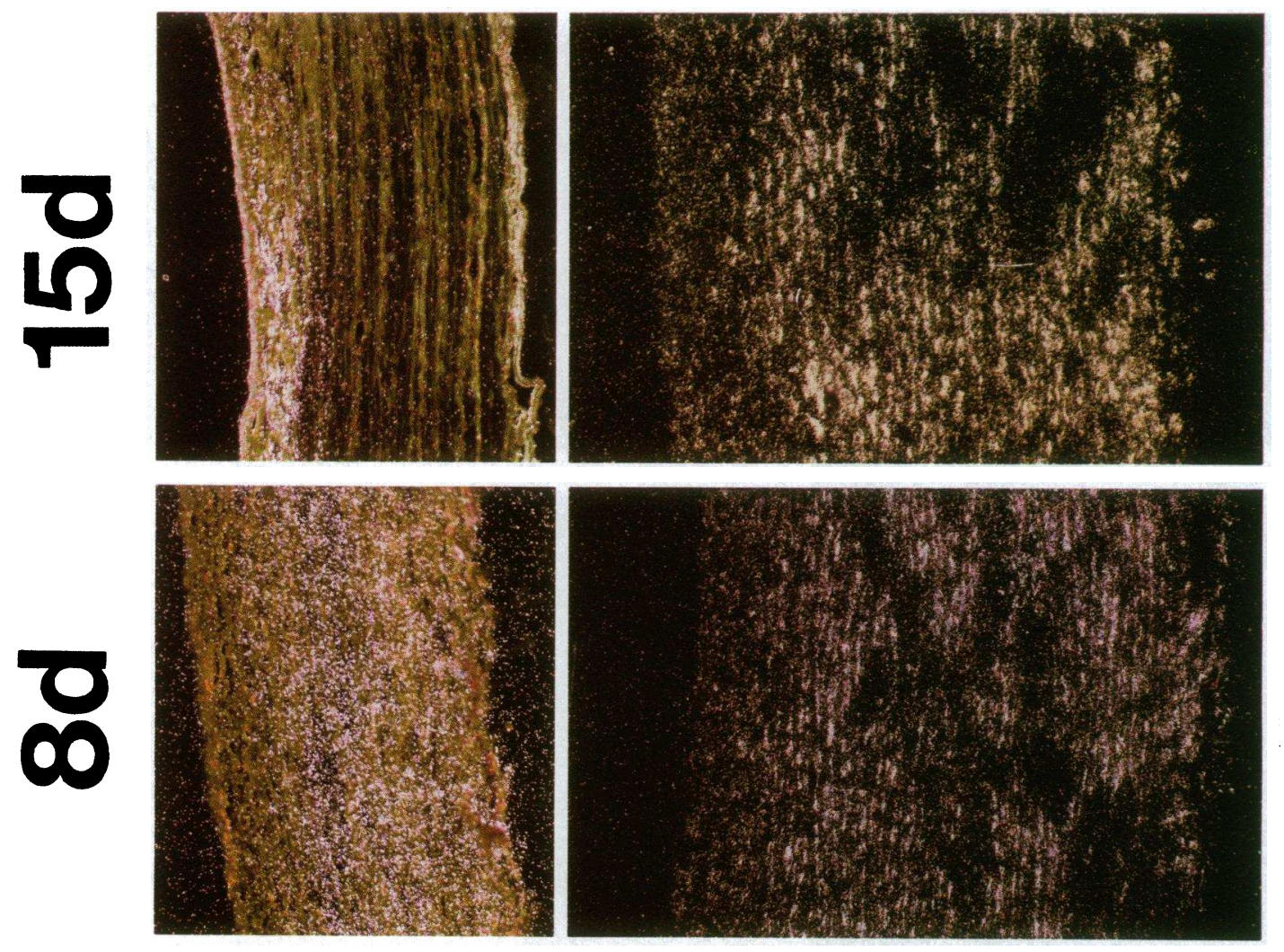

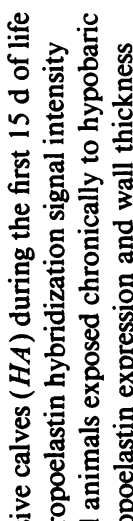

究宫实

可

of

氮悹

啶

希要远

爱芯若

잉

วิे

ส

孚造

흐ㄴㅝㅗㅇ

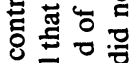

政
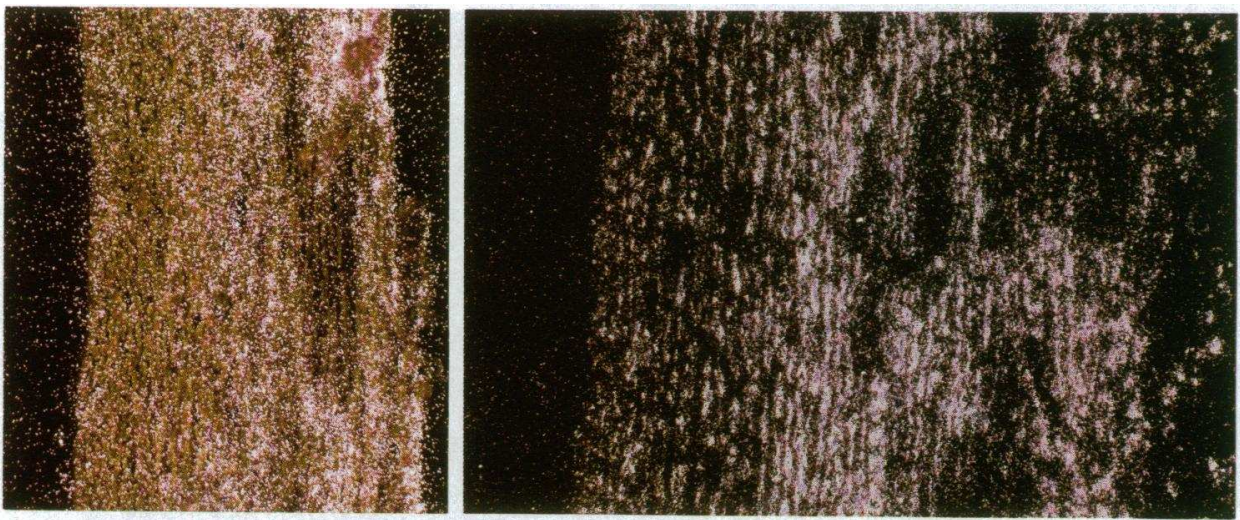

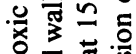

要

政

.

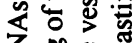

党.

둥

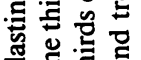

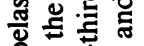

응 氜

논

잉

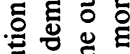

害

总要

密

函

吅 品

诸范

잉. .5

氙

to

递它政

क

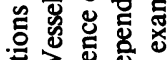

चु

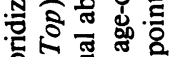

空苞怘

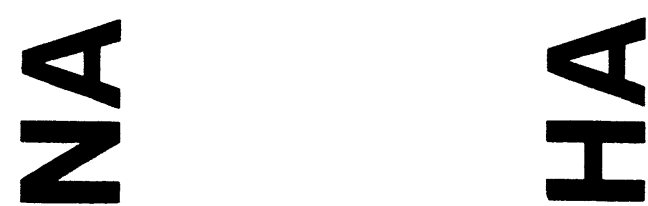

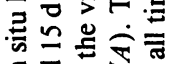

$\leq$ क

म

$\infty$ is

政 $\infty$

运过合造 


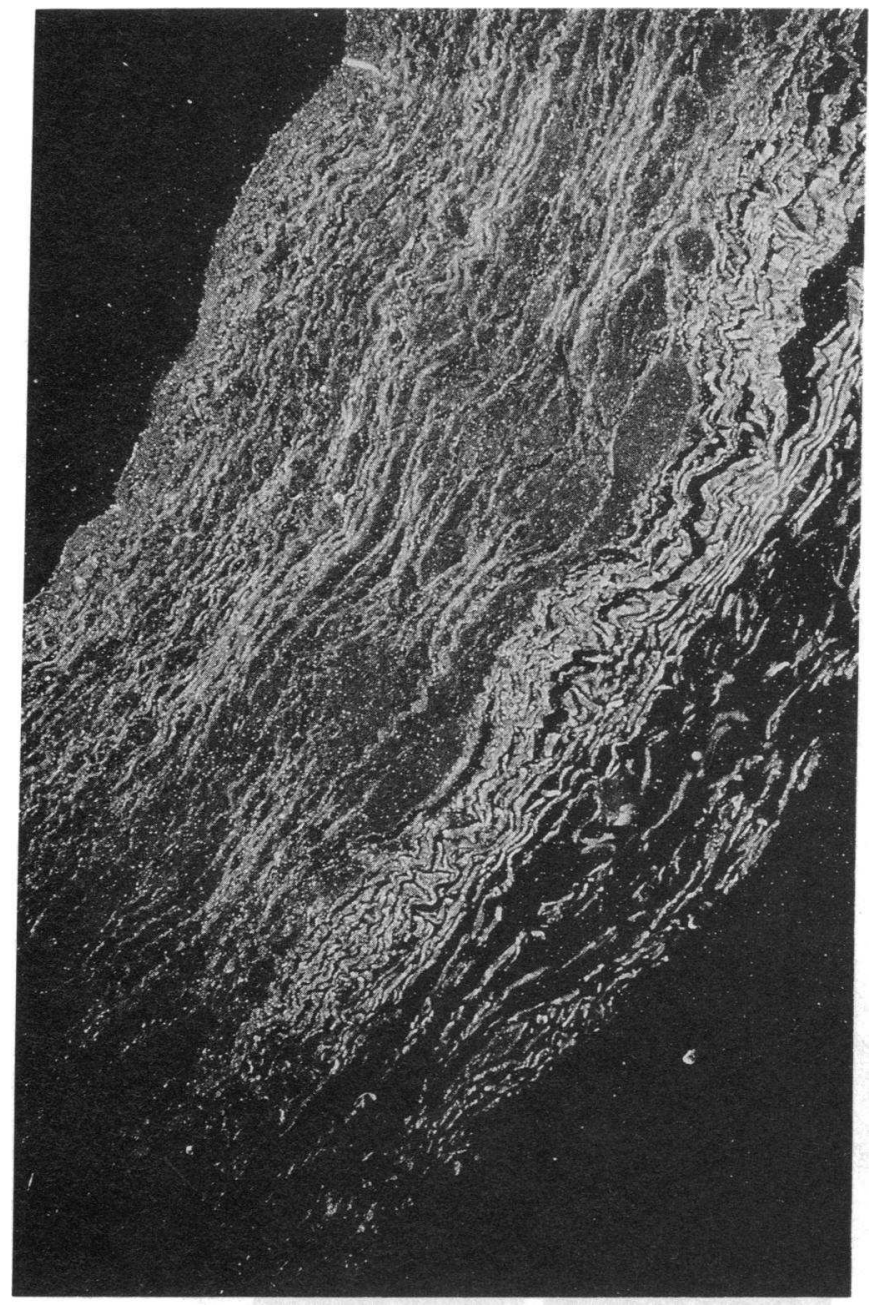

Figure 4. In situ hybridization demonstrating lack of tropoelastin mRNA signal in the mature (1-2-yr-old) pulmonary artery wall. No consistent hybridization signal was observed in lobar pulmonary arteries from mature animals.

with no intervening elastic lamellae. Very consistent was the fact that tropoelastin mRNA expression was greatest in the outer media.

To assess if the changing distribution of tropoelastin mRNA expression was specific to the pulmonary vasculature, we also examined sections of thoracic aorta from control and hypertensive calves. Strong hybridization signal was observed throughout the vessel wall, with the exception of tropoelastin mRNA-negative cell foci similar to those observed in the pulmonary artery. No changes were observed in the distribution pattern of tropoelastin mRNA in the aorta of control or hypertensive calves over the time period during which dramatic changes were observed in the pulmonary artery (Fig. 5).

$R N A$ analysis. Blot hybridizations were done to confirm that in situ hybridization findings predicted steady state mRNA levels. High steady state tropoelastin mRNA levels were observed in the lobar pulmonary arteries of the fetus, a time when pulmonary artery pressure is high and when there is presumably a high degree of wall stress in the pulmonary artery. Consistent with the in situ hybridization findings, tropoelastin mRNA levels progressively declined over the first $15 \mathrm{~d}$ of life in the lobar pulmonary artery of control animals (Fig. 6). This decline was concomitant with the progressive decrease in pulmonary artery pressure and pulmonary vascular resistance over this period of time ( see Fig. 1). On the other hand, tropoelastin mRNA levels remained elevated in animals exposed to hypoxia in whom pulmonary artery pressure did not decline and, in fact, were slightly elevated compared with neonatal calves (Fig. 6). To better evaluate the relationship between tropoelastin mRNA expression and pulmonary artery pressure, we plotted relative tropoelastin levels against pressure (Fig. 7). A highly significant correlation $(r=0.89)$ was demonstrated between pressure and tropoelastin mRNA levels.

Analysis of tropoelastin isoform pattern. Tropoelastin premRNA undergoes extensive alternative splicing resulting in the translation of multiple peptide isoforms, (20-22). We assessed if the production of tropoelastin isoforms in the pulmonary artery followed a developmental pattern similar to that seen in other tissues. Total RNA from late fetal lobar pulmonary artery and nuchal ligament translated three distinct tropoelastin isoforms of 67,65 , and $63 \mathrm{kD}$ (Fig. 8). Consistent with our previous findings (17), the $67-\mathrm{kD}$ isoform in the fetal ligament samples was the least abundant, the 65-kD form was the most prominent, and the $63-\mathrm{kD}$ form was intermediate. In neonatal ligament samples, more of the $67-\mathrm{kD}$ isoform was made, whereas less of the 63-kD isoform was produced. These changes were not due to deletion or retention of exons coding

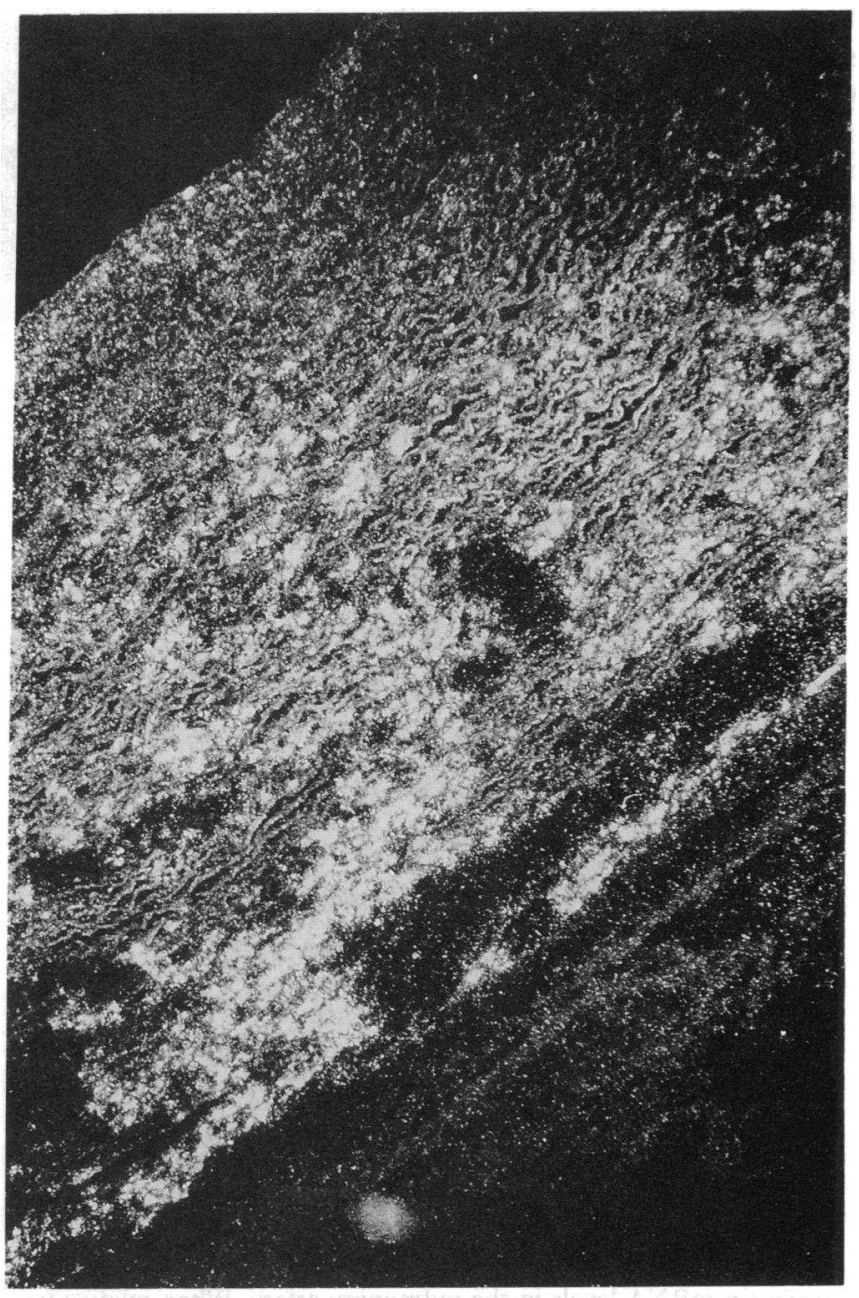

Figure 5. In situ hybridization demonstrating tropoelastin mRNA signal throughout the wall of the thoracic aorta in a 15-d-old control calf. Although signal was observed throughout the entire radius of the vessel, the strongest signal was in the inner half of the vessel. 


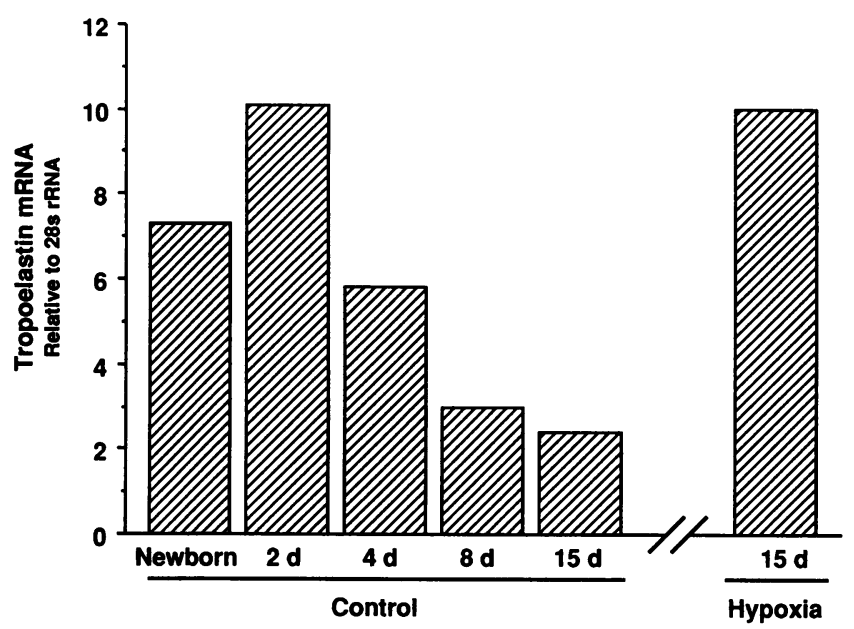

Figure 6. Steady state tropoelastin mRNA levels decrease rapidly during normal development in lobar pulmonary arteries. Densitometric scanning demonstrated that tropoelastin mRNA levels (relative to $28 \mathrm{~s}$ rRNA) declined steadily over the first $15 \mathrm{~d}$ of life. This decline in steady state tropoelastin levels was not observed in animals exposed to hypobaric hypoxia with resultant pulmonary hypertension (15 d hypoxia).

for leucine-rich regions because the same pattern was seen in samples translated in the presence of $\mathrm{L}^{-}\left[{ }^{35} \mathrm{~S}\right]$ cysteine (Fig. 8). Cysteine is encoded by only two exons, and these are not alternatively spliced. In essence, these findings confirm our previous results, which show that the pattern of tropoelastin isoforms produced in the nuchae ligament is developmentally regulated (17).

In contrast, the pattern of tropoelastin isoforms produced by pulmonary artery mRNA did not change in the transition from fetal to extrauterine life, nor was the isoform pattern different in hypertensive animals (Fig. 8). In all samples, whether from fetal, normotensive, or hypertensive calves, the $65-\mathrm{kD}$ form was the most prominent, and the 67- and 63-kD isoforms were synthesized in relatively equal amounts. Thus, these find-

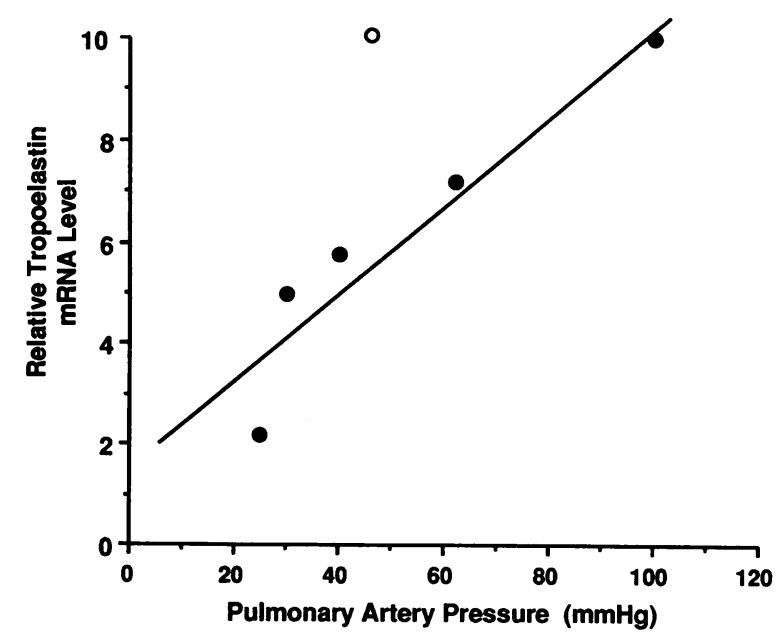

Figure 7. Correlation of pulmonary artery pressure to relative tropoelastin mRNA levels in the pulmonary artery. When relative tropoelastin mRNA levels ( to 28s rRNA) were plotted against pulmonary artery pressure, a strong correlation $(r=0.89)$ was observed. One point $(0)$ from the 2-d-old control animals fell significantly outside this line. ings indicate that the frequency of alternative splicing of tropoelastin pre-mRNA in the pulmonary artery is tissue specific, and that the postnatal development of the tropoelastin isoforms in the pulmonary artery did not follow that for the nuchal ligament. Furthermore, the pattern of tropoelastin isoforms was not affected by hypoxia.

\section{Discussion}

This study demonstrates that changes in hemodynamic stresses after birth are accompanied by specific changes in the amounts and patterns of tropoelastin mRNA expression in the pulmonary artery. While other reports have shown that the changes in hemodynamics occurring in the perinatal period alter pulmonary arterial wall structure and matrix protein content (2330 ), neither overall expression nor pattern of tropoelastin mRNA have been previously addressed. In our study, because normoxic and hypoxic postnatal time periods were comparable, but pressure differences were large, we could, at least in part, separate the effects of time from those of pressure on

\section{Pulmonary Artery}

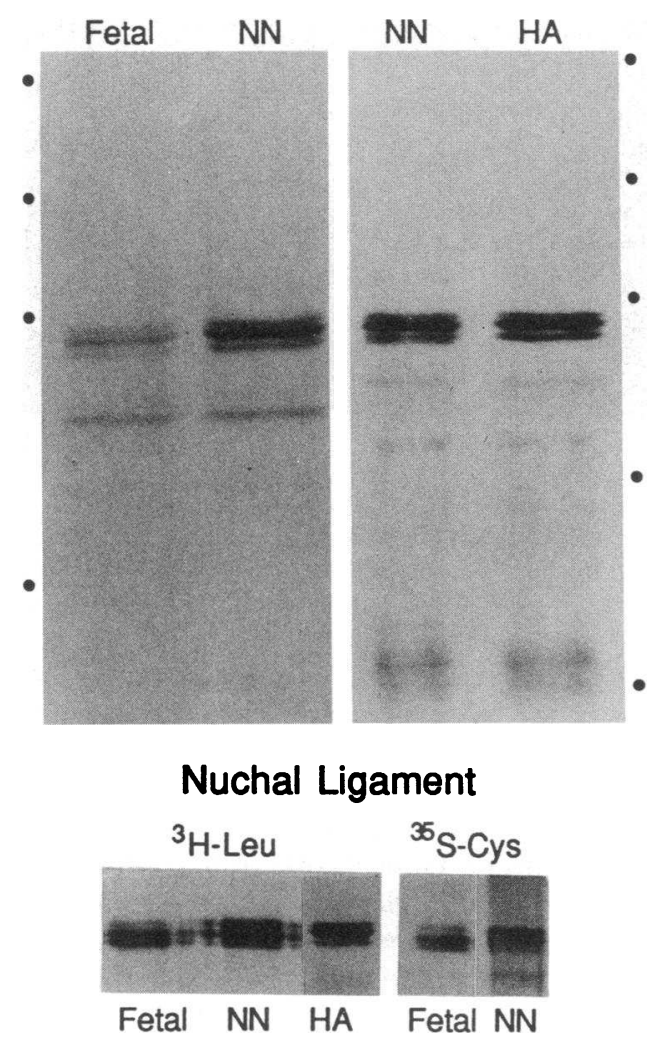

Figure 8. Cell-free translation of tropoelastin isoforms. Total RNA was isolated from nuchal ligament (bottom) and lobar pulmonary artery (top) from term (270-d-old) bovine fetuses (Fetal), from 15d-old control neonatal calves $(N N)$, and from age-matched calves kept at a simulated high altitude for $14 \mathrm{~d}(H A)$. Total RNA $(5 \mu \mathrm{g})$ was translated in vitro in the presence of $\mathrm{L}-\left[{ }^{3} \mathrm{H}\right]$ leucine or $\mathrm{L}-\left[{ }^{35} \mathrm{~S}\right]-$ cysteine, and tropoelastin peptides were immunoprecipitated and resolved by electrophoresis. Migration of tropoelastin isoforms at 67 , 65 , and $63 \mathrm{kD}$ was determined by comparison to ${ }^{14} \mathrm{C}$-labeled molecular mass standards (top, dots on right): myosin ( $200 \mathrm{kD}$ ), phosphorylase $b(92.5 \mathrm{kD})$, bovine serum albumin $(69 \mathrm{kD})$, egg albumin (46 kD), and lactoglobulin A ( $18.4 \mathrm{kD}$; missing from left). Fluorographic exposure was for 7 or $3 \mathrm{~d}$ for the ${ }^{35} \mathrm{~S}$-labeled products. 
tropoelastin mRNA expression. By also examining tropoelastin in the aorta, we could largely separate the effects of oxygenation from those of pressure, because aortic but not pulmonary arterial pressures were mainly independent of hypoxia. The use of in situ hybridization allowed us to study the distribution of the mRNA within the various vessels, and the identification of the tropoelastin mRNA component within total extracted RNA allowed us to estimate the steady state levels present in the vessel wall. The changes both in pressure and in tropoelastin mRNA content and distribution were large, which added confidence to our interpretations relating pressure to tropoelastin changes in the pulmonary artery in the perinatal period.

Elastin production and accumulation is known to be high in the late fetal and newborn periods of life, but to rapidly decrease with increasing maturity $(20,31)$. Our findings in intralobar pulmonary arterial media of a specific pattern for the decrease are supported by the diffuse expression of mRNA in the fetus, the progressive decrease in expression in the outer media, the localization of the expression to the inner media by 2 wk of age, and the absence of expression 2 yr of age. Seemingly then, tropoelastin expression during later periods of development proceeds from the adventitial side towards the lumen. Similarly, the expression of smooth muscle markers, such as $\alpha$-SM-actin, myosin, and metavinculin, appear first in the outer media and progress with time toward the lumen $(32,33)$. Our findings are in close agreement with those in the large arteries of the chick, where tropoelastin mRNA expression begins in the outer media, but later in fetal development production is greatest in that portion of the media nearest the lumen (34).

Radial gradients for tropoelastin in the vessel wall probably reflect developmental changes in the outer media as cells evolve from a secretory to contractile phenotype. Supporting this concept is the observation that cells containing synthetic organelles predominate in the inner media of the newborn pulmonary artery where there is more active matrix production, whereas cells without such organelles and containing an increased abundance of acto-myosin filaments predominate in the outer media (27). These observations support the hypothesis that there is a complex differentiation program in the pulmonary artery wall with a sequence of maturational changes involving changing and multiple SMC phenotypes.

At issue in this study is whether pressure is a part of the stimulus for extinction of tropoelastin mRNA. Control of elastin mRNA induction may differ from that of its extinction. Preliminary data in cell culture suggest that induction is transcriptionally regulated ( 35 ), but that extinction may be controlled by the rate of message degradation (36). If so, cessation of tropoelastin production is controlled by a posttranscriptional process. This study does not address the rate of the mRNA degradation, but it does address hemodynamic factors related to its content and expression in the vascular wall. The fall in content, as shown in Fig. 6, generally accompanies the fall in pressure, which raises, but does not prove, the possibility that pressure is one controller of tropoelastin mRNA. The possibility is supported by our in situ hybridization findings that the expressions in fetal aorta and pulmonary are similar at a time when the pressures are equal, but after birth expression remains present in the aorta where the pressure remains high, and progressively disappears in the pulmonary artery as the pressure falls.

Previous studies have shown that tropoelastin and collagen mRNA content in the aorta are maximal near the time of birth, that for both the expressions differ in the proximal vs. the distal aorta, and that expressions are apparently coupled to the hemodynamic stresses accompanying the development of the circulatory system $(6,31)$. Also, elastin and collagen deposition were similar in the pulmonary arterial trunk and the ascending aorta of the newborn rabbit, but by 2 mo of age, when the aortic pressure greatly exceeded that in the pulmonary artery, the contents of elastin and collagen were also greater (37). Increases in wall tension in both the systemic and pulmonary arterial wall have been shown to stimulate an increase in matrix protein production both in vivo and in vitro (38-40). These changes occur within hours, well before an increase in many other proteins, suggesting that the matrix proteins quickly adapt to assist in maintenance of vessel geometry depending on the stresses that are imposed. Changes in pressure and wall stress are not the only factors controlling tropoelastin expression in the perinatal period. Recent studies have shown increases in elastin accumulation occur in the aorta just before birth in the absence of significant changes in arterial pressure (41). The mechanism of this increase is not known but is felt to be an adaptive response in preparation for subsequent increases in pressure. Nonetheless, the current and previous observations are consistent with the concept that pressure and wall stress likely play an important role in the pulmonary vascular pattern of elastin expression.

If so, then preventing the normal fall in pulmonary arterial pressure after birth should be accompanied by a maintenance of tropoelastin expression in the postnatal period. In this study the fall in pulmonary arterial pressure was prevented by placing the calves in a hypobaric chamber shortly after birth. The findings that tropoelastin mRNA expression persisted in the vessel wall in a pattern similar to that of the fetus, and that tropoelastin mRNA levels did not fall in the postnatal period but were maintained at levels similar to those observed in the aorta, is consistent with the key role of hemodynamic stress in the control of elastogenesis. When the data from the high altitude calves are included in the analysis relating pulmonary pressure to tropoelastin mRNA levels (Fig. 6), the direct correlation between pressure and tropoelastin mRNA levels is preserved.

At one time point, postnatal day 2, the level of tropoelastin mRNA was higher than expected for the pressure observed. This finding may represent a lag in the decay of the mRNA,

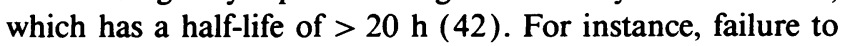
express factors involved in repression of elastin synthesis could result in the maintenance of a highly stable tropoelastin transcript. Thus, the characteristic and marked increase in pulmonary artery elastin expression in neonatal hypertensive animals is not due to an acquired or postnatal activation of tropoelastin synthesis, but rather to a failure to properly repress tropoelastin mRNA expression.

The current findings explain and confirm at the molecular level observations made many years ago from histologic/pathologic specimens. In the fetus, the configuration of the elastic fibers in the pulmonary trunk is similar to that of the aorta. During normal postnatal development marked differences in the arrangement of the network of elastic fibers between the aorta and pulmonary artery are observed (43). When pulmonary hypertension exists from birth, however, the fetal configuration of elastic fiber distribution in the pulmonary artery persists. In contrast, if pulmonary hypertension is acquired later in life, the fetal or aortic pattern of elastic fiber orientation is not observed in the pulmonary artery. Thus, persistence of the fetal pattern of tropoelastin mRNA in the neonate with severe pul- 
monary hypertension is consistent with the idea that hypertension interrupts the normal phenotypic adaptations in vascular SMC required for or associated with the normal transition to extrauterine life. It is possible that other genes involved in the regulation of structure and/or function of the pulmonary circulation are similarly affected in the setting of neonatal pulmonary hypertension.

\section{Acknowledgments}

We thank J. T. Reeves for help and advice, S. Hoffmeister for invaluable technical assistance, and M. McGowan for preparation of the manuscript.

This work was supported by National Institutes of Health grants HL-41040 and HL-48762 to W.C.P. HL-29594 and HL-26499 to R. P. Mecham; HL-46481, HL-14985, and American Lung Association Career Investigation Awards to K. R. Stenmark and W. C. Parks; and HP-27827 and an American Heart Association Clinician Scientist Award to A. G. Durmowicz.

\section{References}

1. McKenzie, J. C., J. Clancy, Jr., and R. M. Klein. 1984. Autoradiographic analysis of cell proliferation and protein synthesis in the pulmonary trunk of rats during the early development of hypoxia-induced pulmonary hypertension. Blood Vessels. 21:80-89.

2. Meyrick, B., and L. Reid. 1979. Hypoxia and incorporation of ${ }^{3} \mathrm{H}$-thymidine by cells of the rat pulmonary arteries and alveolar wall. Am. J. Pathol. 96:51-70.

3. Meyrick, B., and L. Reid. 1982. Normal postnatal development of the media of the rat hilar pulmonary artery and its remodeling by chronic hypoxia Lab. Invest. 46:505-514.

4. Murphy, J. D., M. Rabinovitch, J. D. Goldstein, and L. Reid. 1981. The structural basis of persistent pulmonary hypertension of the newborn infant. $J$. Pediatr. 98:962-967.

5. Noguchi A., and H. Samaha. 1991. Developmental changes in tropoelastin gene expression in the rat lung studied by in situ hybridization. Am. J. Respir. Cell. Mol. Biol. 5:571-578.

6. Davidson, J. M., K. E. Hill, and J. L. Alford. 1986. Developmental changes in collagen and elastin biosynthesis in the porcine aorta. Dev. Biol. 118:103-111.

7. Heim, R. A., R. A. Pierce, S. B. Deak, D. J. Riley, C. D. Boyd, and C. A. Stolle. 1991. Alternative splicing of rat tropoelastin mRNA is tissue-specific and developmentally regulated. Matrix. 11:359-366.

8. Barrineau, L. L., C. B. Rich, A. Przybyla, and J. A. Foster. 1981. Differential expression of aortic and lung elastin genes during chick embryogenesis. Dev Biol. 87:46-51.

9. Tozzi C. A., G. J. Poiani, A. M. Harangozo, C. D. Boyd, and D. J. Riley 1989. Pressure-induced connective tissue synthesis in pulmonary artery segments is dependent on intact endothelium. J. Clin. Invest. 84:1005-1012.

10. Leung, D. Y. M., S. Glagov, and M. B. Matthews. 1977. A new in vitro system for studying cell response to mechanical stimulation. Exp. Cell Res. 109:285-298.

11. Rabinovitch, M., M. A. Konstam, W. J. Gamble, N. Papanicolaov, M. J. Aronovitz, S. Treves, and L. Reid. 1983. Changes in pulmonary blood flow affect vascular response to chronic hypoxia in rats. Circ. Res. 54:432-441.

12. Crouch, E. C., W. C. Parks, J. L. Rosenbaum, D. Chang, L. Whitehouse, L. Wu, E. C. Orton, K. R. Stenmark, and R. P. Mecham. 1989. Regulation of collagen production by medial smooth muscle cells in hypoxic pulmonary hypertension. Am. Rev. Respir. Dis. 1045-1051.

13. Mecham, R. P., L. A. Whitehouse, D. S. Wrenn, W. C. Parks, G. L. Griffin, R. M. Senior, E. C. Crouch, K. R. Stenmark, and N. F. Voelkel. 1987. Smooth muscle-mediated connective tissue remodelling in pulmonary hypertension. Science (Wash. DC). 237:423-426.

14. Prosser, I. W., K. R. Stenmark, M. Suthar, E. C. Crouch, R. P. Mecham, and W. C. Parks. 1989. Regional heterogeneity of elastin and collagen gene expression in intralobar arteries in response to hypoxic pulmonary hypertension as demonstrated by in situ hybridization. Am. J. Pathol. 135:1073-1088.

15. Stenmark, K. R., J. Fasules, D. M. Hyde, N. F. Voelkel, A. Tucker, H. Wilson, and J. T. Reeves. 1987. Severe pulmonary hypertension and arterial adventitial changes in newborn calves at $4300 \mathrm{~m}$. J. Appl. Physiol. 62:821-830.

16. Gonzalez, I. L., J. L. Gorski, T. J. Campen, D. J. Dorney, J. M. Erickson, J. E. Sylvester, and R. D. Schmickel. 1978. Variation among human 28S ribosomal RNA genes. Proc. Natl. Acad. Sci. USA. 82:7666-7670.
17. Parks, W. C., H. Secrist, L. C. Wu, and R. P. Mecham. 1988. Developmental regulation of tropoelastin isoforms. J. Biol. Chem. 263:4416-4423.

18. Orton, E. C., J. T. Reeves, and K. R. Stenmark. 1988. Pulmonary vasodilation in calves with structurally-altered pulmonary vessels and pulmonary hypertension. J. Appl. Physiol. 65:2459-2467.

19. Reeves, J. T., F. S. Daoud, and M. Gentry. 1972. Growth of the fetal calf and its arterial blood pressure, blood gases, and hematologic data. J. Appl. Physiol. 32:240-244.

20. Parks, W. C., and S. B. Deak. 1990. Tropoelastin heterogeneity: Implications for protein function and disease. Am. J. Respir. Cell Mol. Biol. 2:399-406.

21. Wrenn, D. S., W. C. Parks, L. A. Whitehouse, E. C. Crouch, U. Kucich, J. Rosenbloom, and R. P. Mecham. 1987. Identification of multiple tropoelastins secreted by bovine cells. J. Biol. Chem. 262:2244-2249.

22. Yeh, H., N. Ornstein-Goldstein, Z. Indik, P. Shepard, N. Anderson, J. C. Rosenbloom, G. Cicila, K. Yoon, and J. Rosenbloom. 1987. Sequence variation of bovine elastin mRNA due to alternative splicing. Collagen Relat. Res. 7:235247.

23. Ardran, G. M., G. S. Dawes, M. L. Pritchard, S. R. M. Reynolds, and D. G. Wyatt. 1952. The effect of ventilation of the fetal lungs upon the pulmonary circulation. J. Physiol. 118:12-22.

24. Cassin, S., G. S. Dawes, J. C. Mott, B. B. Ross, and L. B. Strang. 1964. The vascular resistance of the foetal and newly ventilated lungs of the lamb. J. Physiol. 171:61-79.

25. Greenwald, S. E., C. L. Berry, and S. G. Haworth. 1982. Changes in the distensibility of the intrapulmonary arteries in the normal newborn and growing pig. Cardiovasc. Res. 16:716-725.

26. Hall, S. M., and S. G. Haworth. 1986. Normal adaptation of the pulmonary arterial intima to extrauterine life in the pig: ultrastructural studies. $J$. Pathol. 149:55-66.

27. Hall, S. M., and S. G. Haworth. 1987. Conducting pulmonary arteries:structural adaptation to extrauterine life in the pig. Cardiovasc. Res. 21:208-216.

28. Haworth, S. G., and A. A. Hislop. 1981. Adaptation of the pulmonary circulation to extra-uterine life in the pig and its relevance to the human infant. Cardiovasc. Res. 15:108-119.

29. Meyrick, B., and L. Reid. 1982. Normal postnatal development of the media of the rat hilar pulmonary artery and its remodeling by chronic hypoxia. Lab. Invest. 46:505-514.

30. Reeves, J. T., and J. E. Leathers. 1964. Circulatory changes following birth of the calf and the effect of hypoxia. Circ. Res. 15:343-354.

31. Keeley, F. W., R. A. Hussain, and D. J. Johnson. 1990. Pattern of accumulation of elastin and the level of mRNA for elastin in aortic tissue of growing chickens. Arch. Biochem. Biophys. 282:226-232.

32. Rosenquist, T. H., and A. C. Beall. 1990. Elastogenic Cells in the Developing Cardiovascular System. Ann. NY Acad. Sci. 588:106-119.

33. Frid, M. G., R. P. Mecham, E. O. Moiseeva, and K. R. Stenmark. 1993. Identification of phenotypically distinct smooth muscle cell populations in mature and developing bovine pulmonary arteries. Am. Rev. Respir. Dis. 147(4):A493.

34. Selmin, O., D. Volpin, and G. M. Bressan. 1991. Changes of cellular expression of mRNA for tropoelastin in the intraembryonic arterial vessels of developing chick revealed by in situ hybridization. Matrix. 11:347-358.

35. Pierce, R. A., W. I. Mariencheck, S. Sandcfur, E. C. Crouch, and W. C. Parks. 1993. Glucocorticoid-mediated transcriptional upregulation of tropoelastin expression during fetal lung development. J. Biol. Chem. In press.

36. Pierce, R. A., and W. C. Parks. 1992. 1-25-dihydroxyvitamin D3 represses tropoelastin expression by a post-transcriptional mechanism. J. Biol. Chem. 267:11593-11599.

37. Leung, D. Y. M., S. Glagov, and M. B. Mathews. 1977. Elastin and collagen accumulation in rabbit ascending aorta and pulmonary trunk during postnatal growth. Circ. Res. 41:316-323.

38. Leung, D. Y. M., S. Glagov, and M. B. Mathews. 1976. Cyclic stretching stimulates synthesis of matrix components by arterial smooth muscle cells in vitro. Science (Wash. DC). 19:475-477.

39. Keeley, F. W., and D. J. Johnson. 1986. The effect of developing hypertension on the synthesis and accumulation of elastin in the aorta of the rat. Biochem. Cell Biol. 64:38-43.

40. Tozzi, C. A., G. J. Poiani, A. M. Harangozo, C. D. Boyd, and D. J. Riley. 1989. Pressure-induced connective tissue synthesis in pulmonary artery segments is dependent on intact endothelium. J. Clin. Invest. 84:1005-1012.

41. Bendeck, M. P., and R. L. Langille. 1991. Rapid accumulation of elastin and collagen in the aortas of sheep in the immediate perinatal period. Circ. Res. 69:1165-1169.

42. Parks, W. C., M. E. Kolodziej, and R. A. Pierce. 1992. Phorbol ester-mediated down regulation of tropoelastin expression is controlled by a post-transcriptional mechanism. Biochemistry. 31:6639-6645.

43. Heath, D., E. H. Wood, J. W. DuShane, and J. E. Edwards. 1959. The structure of the pulmonary trunk at different ages and in cases of pulmonary hypertension and pulmonary stenosis. J. Pathol. Bacteriol. 77:443. 